\title{
Qual a contribuição da consciência morfológica das crianças na precisão de leitura de palavras e compreensão de texto no português?
}

Silvia Brilhante Guimarães. Universidade Salgado de Oliveira.

Márcia Maria Peruzzi Elia da Mota. Universidade do Estado do Rio de Janeiro.

\section{Resumo}

Este estudo investiga a afirmação de Justi e Roazzi (2012) de que a consciência morfológica não contribui, de forma independente, para a leitura, quando se controla a influência das habilidades cognitivas e da consciência fonológica. Cento e quatorze crianças provenientes do $2^{\circ} \mathrm{e} 4^{\circ}$ ano do Ensino Fundamental de uma escola pública participaram do estudo em que foram avaliadas quanto à consciência fonológica, às habilidades cognitivas e à consciência morfológica. Os resultados mostraram que, após o controle da idade, as habilidades cognitivas e a consciência fonológica, a consciência morfológica derivacional ainda contribuiu para a leitura de palavras. Não houve resultados significativos das contribuições da consciência morfológica para a compreensão da leitura. Esses resultados indicam que a consciência morfológica é relevante para a aquisição de leitura de palavras em português do Brasil e levantam a questão se a contribuição para compreensão de texto não é indireta, via leitura de palavras.

Palavras-chave: consciência morfológica; leitura; compreensão de texto; alfabetização.

\begin{abstract}
What morphological awareness of the contribution of children in word reading accuracy and reading comprehension in Portuguese? This study investigates Justi and Roazzi's (2012) affirmation that morphological awareness does not contribute independently to reading when cognitive and phonological awareness controls are applied. One hundred and fourteen children from $2^{\text {nd }}$ and $4^{\text {th }}$ grade public schools participated in the studies. Children were evaluated on phonological awareness, cognitive abilities and morphological awareness. The results showed that after controlling for age, cognitive abilities and phonological awareness, derivational morphology still contributed to word reading. There was not significant result with the contributions of morphological awareness to reading comprehension. These results indicate the morphological awareness is relevant to reading acquisition in Brazilian Portuguese.
\end{abstract}

Keywords: morphological awareness; reading; reading comprehension; literacy.

\section{Resumen}

¿Cual es la contribución de la conciencia morfológica de los niños en la precisión de lectura de palabras y la comprensión de texto en el portugués? Este estudio investiga la afirmación de Justi y Roazzi (2012) en el sentido de que la conciencia morfológica no contribuye de forma independiente a la lectura cuando se aplican los controles cognitivos y de conciencia fonológica. Ciento catorce niños y niñas del $2^{\circ}$ y $4^{\circ}$ año de educación primaria participaron del estudio. Los niños fueron evaluados en materia de conciencia fonológica, habilidades cognitivas y conciencia morfológica. Los resultados mostraron que tras el control de la edad, las habilidades cognitivas y la conciencia fonológica, la conciencia morfológica derivativa contribuye también hacia la lectura de palabras. No se observaron resultados significativos de las contribuciones de conciencia morfológica en la comprensión lectora. Los resultados muestran que la conciencia morfológica es relevante para la adquisición de lectura de palabras en el portugués de Brasil y levantan la cuestión de si la comprensión de texto no ocurre indirectamente por medio de la lectura de palabras.

Palabras clave: conciencia morfológica; lectura; comprensión lectora; alfabetismo. 
Nas últimas décadas, a ciência da leitura vem apontando a consciência morfológica como uma das habilidades cognitivas preditivas da leitura e da escrita (Deacon \& Kirby, 2004; Kirby et al., 2012; Kuo \& Anderson, 2006; Nunes, Bindman, \& Bryant, 1997; Nunes $\&$ Bryant, 2006). A consciência morfológica refere-se à capacidade de refletir e manipular, de forma explícita, os morfemas e as regras de formação de palavras em um idioma (Carlisle, 1995). Para entender a importância da consciência morfológica na leitura, é necessário compreender o que são os morfemas e quais papéis eles exercem na ortografia.

Os morfemas são considerados as unidades mínimas linguísticas, dotadas de significado, que integram as palavras (Bechara, 2009). Eles são divididos em: radical e afixo (sufixo e prefixos). O radical exprime o significado básico da palavra. Os afixos são morfemas que acompanham o radical, podendo modificar o significado ou a classe gramatical da palavra. Por exemplo, a palavra "infelizmente" possui três morfemas "in" (prefixo) + feliz (radical) + "mente" (sufixo). Os morfemas assumem a função derivacional ou flexional. A derivação é constituída pela formação de palavras, a partir de uma palavra primitiva mais os afixos (sufixos ou prefixos). Por exemplo, a palavra "afetuosa" contém dois morfemas: o radical "afeto" mais o sufixo "oso" que transforma o substantivo em adjetivo. A flexão é a adequação da palavra ao contexto sintático devido às exigências das concordâncias de gênero, número e grau (Laroca, 2005).

A consciência morfológica é uma habilidade cognitiva que parece ter um papel significativo na leitura (Deacon \& Kirby, 2004; Kirby et al., 2012; Kuo $\&$ Anderson, 2006). A ortografia de muitas palavras da língua depende da morfologia. Saber do significado dos morfemas pode auxiliar a criança a entender a semântica da palavra, ampliando, com isso, o seu repertório lexical e, consequentemente, a compreensão de textos. Ao conhecerem os valores semânticos desses prefixos, as crianças podem criar hipóteses sobre o significado da palavra desconhecida. Por exemplo, os vocábulos "atenção" e "desatenção" são da mesma classe gramatical (substantivo), porém, possuem significados diferentes pelo uso da prefixação des-. Esse morfema propicia uma modificação semântica na palavra "atenção", dando um significado de "falta de atenção".

$\mathrm{Na}$ língua inglesa, há um corpo crescente de pesquisas empíricas indicando que a consciência morfológica contribui para a capacidade de leitura de palavras e de compreensão de textos (por exemplo, Carlisle, 1995; Deacon, Benere, \& Pasquarella, 2013; Deacon \& Kirby, 2004; Kirby et al., 2012; Kuo \& Anderson, 2006; Kruk \& Bergman, 2013; Mahony, Singson, \& Mann, 2000; Nagy, Berninger, \& Abbott, 2006; Nunes, Bryant, \& Barros, 2012; Tong, Deacon, Kirby, Cain, \& Parrila, 2011). O inglês é uma língua alfabética que apresenta profundidade ortográfica (Seymour, Aro, \& Erskine, 2003). Nesse sentido, a consciência morfológica ajuda na alfabetização, uma vez que a ortografia de muitas palavras depende da morfologia (Nunes \& Bryant, 2006).

Para os falantes da língua inglesa, a consciência morfológica pode ser uma habilidade importante para a leitura (Deacon \& Kirby, 2004; Kirby et al., 2012). No estudo de Deacon e Kirby (2004), os autores avaliaram longitudinalmente crianças do $2^{\circ}$ ao $5^{\circ}$ ano escolar. Verificaram a contribuição da consciência morfológica para a leitura de palavras, pseudopalavras e compreensão de texto. Os dados foram submetidos à análise de regressão hierárquica, tendo como variáveis de controle a inteligência (verbal e não verbal) e a consciência fonológica. Os autores utilizaram esses controles cognitivos, pois são variáveis que influenciam a leitura. A retirada desses efeitos foi importante para não superestimar o papel da consciência morfológica. Os resultados mostraram que, mesmo depois de aplicados os controles cognitivos, a consciência morfológica continuou explicando $9 \%$ ( $3^{\circ}$ ano), $10 \%$ ( $4^{\circ}$ ano) e $11 \%$ ( $5^{\circ}$ ano) da variância da leitura de pseudopalavras; $8 \%$ ( $3^{\circ}$ ano), $8 \%$ ( $4^{\circ}$ ano) e $5 \%$ ( $5^{\circ}$ ano) da variância de leitura de palavras e a $8 \%$, ( $3^{\circ}$ ano), $10 \%$ ( $4^{\circ}$ ano) e $7 \%$ ( $5^{\circ}$ ano) da variância de compreensão de textos. Na compreensão de texto, a contribuição da consciência morfológica foi um pouco maior do que a consciência fonológica. Quando as pesquisadoras controlaram o efeito da inteligência e depois da consciência morfológica, a consciência fonológica explicou $8 \%$ ( $3^{\circ}$ ano), $8 \%$ ( $4^{\circ}$ ano) e $5 \%$ ( $5^{\circ}$ ano) da variância da compreensão de texto.

O português é considerado uma língua que está no meio do espectro da profundidade ortográfica. As inconsistências na relação fonemas e grafema são maiores do que em línguas como o espanhol e o finlandês, mas menores que no inglês e no francês (Seymour et al., 2003). Nesse caso, é difícil prever se a estrutura morfológica da língua terá um papel importante ou não na leitura e escrita de palavras. É possível pensar que, no português, a habilidade metalinguística que contribuirá para a leitura será a de refletir sobre os sons 
da fala. Vários estudos têm demonstrado a importância dessa habilidade metalinguística chamada consciência fonológica para a leitura no português (Capovilla \& Capovilla, 1998; Cardoso-Martins, 1995; CardosoMartins, Mesquita, \& Ehri, 2011; Maluf \& Barrera, 1997; Rego \& Buarque, 1997; Roazzi, Roazzi, Justi \& Justi, 2013).

Todavia, estudos nacionais apontaram para uma relação da consciência morfológica com a escrita (Justi \& Roazzi, 2012; Mota, Anibal, \& Lima, 2008; Mota, Santos et al., 2008) e a leitura (Freitas \& Mota, 2015, Miranda \& Mota, 2013, Mota, Santos et al., 2012) mesmo depois de retirado a influência da consciência fonológica. Essa variável cognitiva pode compartilha variância com a consciência morfológica. Dessa forma, controlar a influência dessa habilidade nos estudos da consciência morfológica nos possibilita enxergar se há uma contribuição única da consciência morfológica para a leitura no português.

Mota, Anibal e Lima (2008) realizaram um estudo transversal com 51 crianças ( $2^{\circ}$ e $3^{\circ}$ anos) com a finalidade de verificar qual a influência da consciência morfológica (tarefa de analogia derivacional) na precisão de leitura e escrita. Os resultados mostraram que a pontuação da tarefa de analogia derivacional influenciou a escrita, mesmo controlando a idade das crianças e a tarefa de consciência fonológica (tarefa de identificação de rima). A tarefa de consciência fonológica no estudo não teve correlação com a leitura de palavras e por isso não foi usada como medida de controle. Como as tarefas de consciência fonológica costumam estar relacionadas com a leitura, pode ter havido um problema na escolha da tarefa nesse estudo. Sendo assim, para análise da leitura, os resultados mostraram que a consciência morfológica contribuiu para a leitura, após o controle das idades das crianças, não sendo possível verificar se a contribuição foi independente da consciência fonológica. Esse resultado mostra que a consciência morfológica, independentemente da idade das crianças, teve uma influência na leitura precisa das palavras, mas ainda não responde se a consciência morfológica pode ter uma contribuição independente da consciência fonológica.

A despeito de o estudo de Justi e Roazzi (2012) ter tentado avançar nessa questão, não encontrou resultados que corroborassem a contribuição da consciência morfológica (CM) para a leitura, vez que encontraram evidências para essa relação apenas com a escrita. Os resultados do estudo, realizado com 94 crianças do $4^{\circ}$ ano do Ensino Fundamental, indicaram que consciência morfológica teve uma contribuição independente da CM para a escrita. Na análise de regressão, indicou-se que a consciência morfológica explicou 3\% da variância da escrita depois do controle da idade, inteligência, processamento fonológico e nomeação seriada rápida. Na leitura (precisão e fluências), a consciência morfológica não foi significativa, como já afirmado. Vale destacar que as variáveis de controle desse estudo foram muito mais robustas do que as do estudo de Mota et al. (2008). Esses autores utilizaram a medida de processamento fonológico (tarefa de Spoonerismo, subtração de fonema e memória fonológica), além da nomeação seriada rápida.

Uma questão colocada por Justi e Roazzi (2012) sobre a diferença de contribuição da consciência morfológica na leitura e escrita seria em virtude do mapeamento da relação letra e som. Na leitura, a relação entre letra e som é mais estável que na escrita. Segundo Justi e Roazzi (2012), os testes de leitura eram compostos por muitas palavras regulares, o que pode ter influenciado a não contribuição da consciência morfológica na leitura.

Miranda e Mota (2013) realizaram um estudo transversal com 57 crianças do $2^{\circ}$ e $3^{\circ}$ ano do Ensino Fundamental que foram submetidas a testes padronizados e a tarefas de consciência morfológica e fonológica. A pesquisa investigou se a consciência morfológica derivacional contribui para precisão de leitura de palavras, sem influência da consciência fonológica. Os resultados mostraram que a consciência morfológica (tarefa de analogia derivacional), não foi significativa para a leitura, quando a influência da tarefa de consciência fonológica (tarefa de Spoonerismo - substituição de fonemas na palavra) foi retirada. No entanto, quando substituíram a tarefa de consciência fonológica pela subtração de fonemas (retira-se o fonema da palavra), a consciência morfológica explicou $2 \%$ e $4 \%$ à variância da precisão de leitura de palavras.

Freitas e Mota (2015) realizaram um estudo com 52 crianças, matriculadas no $4^{\circ}$ e $5^{\circ}$ ano do Ensino Fundamental, com intuito de verificar os achados de Justi e Roazzi (2012). O estudo verificou se a consciência morfológica (tarefas de analogia flexional e derivacional) exerce influência na leitura (precisão de leitura de palavras e compreensão de texto), após a retirada do efeito da inteligência não verbal e da consciência fonológica. A tarefa de consciência fonológica escolhida foi a de Spoonerismo. Os autores dividiram a tarefa em 
duas partes. Na primeira parte, a criança manipula o fonema inicial da palavra e, na segunda, os fonemas iniciais de palavras compostas como/milho verde/para /vilho merde/. Em ambas as tarefas, quando foi utilizada como controle a consciência morfológica (apenas a tarefa de analogia derivacional), houve uma contribuição única para a leitura precisa das palavras. O mesmo efeito não foi encontrado na compreensão de texto. Os autores encontraram uma contribuição de $5 \%$ e 5,9\% da consciência morfológica derivacional, depois de retirar influência da consciência fonológica (Spoonerismo parte 1 e Spoonerismo parte 2, respectivamente) para leitura de palavras.

Nesse sentido, os estudos nacionais indicam que, embora a consciência morfológica possa ter influência na leitura no português do Brasil, essa influência tem sido demonstrada para precisão de palavras, sendo ainda controversa, pois também parece depender do controle que é usado para o processamento fonológico. Essa divergência aparece nos estudos nacionais citados. No estudo de Justi e Roazzi, (2012), como fora mencionado, o controle utilizado foi mais robusto, pois utilizaram as duas tarefas de consciência fonológica (Spoonerismo e subtração de fonema na palavra), juntamente com uma medida de memória de trabalho (dígito do WISCIII), compondo uma medida de processamento fonológico. Ao mesmo tempo, ao incluir a memória de trabalho e controlar a inteligência, podem ter tornado os controles muito conservadores. No estudo de Miranda e Mota (2013), o resultado foi significativo apenas com a tarefa de subtração de fonemas e não com a Spoonerismo. No estudo de Freitas e Mota (2015), por outro lado, encontraram resultado significativo mesmo com a tarefa de Spoonerismo que é uma tarefa mais complexa que a de subtração de fonemas.

Diante desses resultados contraditórios, ainda presentes nos estudos nacionais, faz-se necessária a reaplicação de estudos com a finalidade de encontrar mais evidências entre a relação da consciência morfológica e da leitura. Nesse sentido, o presente estudo teve como objetivo investigar se há contribuição da consciência morfológica para leitura de palavras e compreensão de texto no português, depois da retirada dos efeitos da consciência fonológica e inteligência (verbal e não verbal). Essas medidas foram utilizadas como variáveis de controle para não inflar os efeitos da consciência morfológica na leitura. Além de disso, o estudo verificou a proporção da variância atribuída à consciência morfológica e fonológica na leitura.

\section{Método}

\section{Participantes}

A amostra da pesquisa contou com 114 crianças do Ensino Fundamental, 62 do $2^{\circ}$ ano $(M=94,2$ meses; $D P=$ 5 meses) e 52 do $4^{\circ}$ ano ( $M=121,6$ meses; $D P=7$ meses) de uma escola pública do Rio de Janeiro. A seleção da escola atendeu ao critério de conveniência. O critério para incluir essas crianças na pesquisa foi a assinatura, pelos seus responsáveis, do Termo de Consentimento Livre e Esclarecido. Esse termo seguiu as normas do Comitê de Ética e Pesquisa - protocolo da pesquisa $\mathrm{n}^{\circ}$ 084.3.2012, parecer $n^{\circ}$ 019/2013.

\section{Instrumentos}

Avaliação de consciência fonológica. Utilizou-se a tarefa de Spoonerismo de Cardoso-Martins (comunicação pessoal, 14 de agosto de 2008). A finalidade da tarefa é medir a capacidade da criança de manipular fonemas. A tarefa é dividida em duas partes, cada uma com 10 itens de teste. Na primeira parte, a criança tem que realizar a troca de um fonema em uma palavra. Na segunda, deve manipular a troca de fonemas em duas palavras. Para cada acerto, foi marcado um ponto.

Avaliação de consciência morfológica. Foi realizada a tarefa de Analogia de palavras (adaptada de Nunes et al., 1997) que tem como finalidade averiguar a manipulação consciente da criança sobre as modificações morfológicas das palavras. A tarefa, que segue o princípio de que 'A' está para ' $B$ ', assim como ' $C$ ' está para ' $D$ ', é dividida em duas partes. Na primeira, os itens foram baseados na consciência morfológica derivacional e, na segunda, na flexional.

A tarefa de consciência morfológica derivacional consta com três itens de treinamento e dezessete itens experimentais. Dos itens experimentais, nove são compostos pela derivação sem mudança de classe gramatical, mas com modificação semântica, e oito itens com mudança de classe gramatical (adjetivo/substantivo/verbo).

A tarefa de consciência da morfológica flexional é composta por quatro itens de treino e de quinze itens experimentais. Dos itens experimentais, seis são referentes a flexões de gênero (feminino/masculino), quatro de número (singular/plural), cinco se referem ao modo verbal (presente/passado/futuro) e dois à pessoa ( $1^{\text {a }}$ e $3^{\text {a }}$ singular-presente; $1^{\text {a }}$ e $3^{\text {a }}$ singular- passado). O escore consistiu no número de itens respondidos corretamente. Para cada acerto, foi marcado um ponto. 
Avaliação de precisão de leitura de palavra. Subteste de leitura do Teste de Desempenho Escolar - TDE (Stein, 1994): a criança deve ler, em voz alta, um conjunto de 70 palavras isoladas. O subteste foi administrado e corrigido de acordo com as instruções e os procedimentos especificados no manual. Assim, para cada acerto, é dado um ponto e, para cada erro, zero ponto, perfazendo um total de 70 pontos.

Avaliação de compreensão de texto. Subteste de compreensão de texto das Provas de Avaliação dos Processos de Leitura - (Capellini, Oliveira, \& Cuetos, 2010): a tarefa consiste em quatro textos (dois narrativos e dois expositivos), cada um seguido por duas perguntas inferenciais e duas literais. A aplicação e a correção dos testes seguiram as orientações do manual da PROLEC.

Avaliação da inteligência verbal e não-verbal. Wechsler Intelligence Scale for Children - WISC III (Wechsler, 1991). Foram aplicados dois subtestes da Escala, quais sejam: a) subteste de inteligência verbal (domínio lexical) - subteste de vocabulário em que uma série de palavras é apresentada oralmente e a criança deve defini-las oralmente; b) subteste de inteligência não verbal - subteste de cubos, composto por um conjunto de padrões geométricos bidimensionais, feitos com cubos ou impressos, que a criança reproduz usando cubos de duas cores. Os escores ponderados foram computados para a realização das análises estatísticas. A correção do teste respeitou o manual do WISC III.

\section{Procedimentos}

As avaliações ocorreram em três sessões de aproximadamente 40 minutos cada. Na primeira, foram realizadas as aplicações dos subtestes do WISCIII de vocabulário e cubos. Na segunda sessão, ocorreu a aplicação das medidas metalinguísticas (consciência fonológica e consciência morfológica). Na terceira sessão, foram aplicados os testes de precisão de leitura de palavras (TDE) e o de compreensão de texto (PROLEC).

Para o TDE, WISC e PROLEC foram dadas as instruções do manual. Na tarefa de analogia gramatical, o aplicador pronunciou um par de palavras, por exemplo, "belo" e "beleza", dizendo, depois, outra palavra: "puro". Foi solicitado à criança que completasse, apropriadamente, o par. Para acertar a tarefa, a criança teria que perceber as transformações morfológicas do primeiro par de palavras e aplicá-lo no segundo par, respondendo "pureza".
A tarefa de consciência fonológica foi dividida em duas partes. Na primeira parte da tarefa de Spoonerismo, foi perguntado para a criança: "como podemos falar a palavra "gato" se o som/g/for trocado pelo som/r/?". Na segunda parte da tarefa, foram faladas para a criança duas palavras, como, por exemplo, "milho verde", sendo, depois, pedido a ela que substituísse o primeiro som da primeira palavra pelo primeiro som da segunda palavra, devendo ela falar "vilho merde".

\section{Resultados}

As estatísticas descritivas e a fidedignidade de todas as medidas são apresentadas na Tabela 1. Para verificar a normalidade das variáveis, foram calculados os escores das divisões das skewness pelo erro padrão da skewness. O resultado deveria de estar no intervalo de > -2 e $<2$ (Field, 2009). As variáveis leitura de palavras/TDE, Spoonerismo $1^{\text {a }}$ parte, vocabulário e cubo apresentaram distribuições assimétricas, com valores de -6,2; -2,21; 2,4 e 4,3 respectivamente. Nesse sentido, as distribuições assimétricas negativas foram submetidas a transformações logarítmicas, Ln (valor máximo + 1- escores da variável) e as assimétricas positivas por radiciação (escores da variável) (Field, 2009). Após essas transformações, as variáveis apresentaram uma distribuição normal. Todas as análises posteriores foram realizadas com as variáveis transformadas.

Tabela 1. Estatísticas Descritivas e Fidedignidade das Tarefas Administradas.

\begin{tabular}{lcccc}
\hline Tarefas & $\begin{array}{c}\text { Escore } \\
\text { total }\end{array}$ & M & DP & $\begin{array}{c}\text { Alfa de } \\
\text { Cronbach }\end{array}$ \\
\hline CF1 & 10 & 5,9 & 3 & 0,85 \\
CF2 & 20 & 10,8 & 7 & 0,85 \\
CM Derivacional & 17 & 8,4 & 4 & 0,86 \\
CM Flexional & 17 & 9,7 & 4 & 0,85 \\
Leitura de palavras & 70 & 61 & 8,8 & 0,98 \\
$\begin{array}{l}\text { Compreensão de } \\
\text { texto }\end{array}$ & 16 & 9,5 & 2,6 & 0,94 \\
$\begin{array}{l}\text { Vocabulário/WISCIII } \\
\text { (escore ponderado) }\end{array}$ & 19 & 11 & 3,7 & 0,79 \\
$\begin{array}{l}\text { Cubo/WISC III (escore } \\
\text { ponderado) }\end{array}$ & 19 & 9,5 & 3,5 & 0,82 \\
\hline
\end{tabular}

Nota. CF1 = consciência fonológica/Spoonerismo $1^{\text {a }}$ parte; CF2 = consciência fonológica/Spoonerismo $2^{\mathrm{a}}$ parte; $\mathrm{CMF}=$ consciência morfológica flexional; $\mathrm{CMD}=$ consciência morfológica derivacional.

As correlações entre as medidas de leitura, habilidades metalinguísticas, inteligência (verbal e 
não-verbal) e idades são apresentados na Tabela 2. $\mathrm{Na}$ análise das correlações de Pearson, foi evidenciado que as medidas dos escores de consciência morfológica (CM) foram significativamente correlacionadas de maneira moderada e positiva com a precisão de leitura de palavras (CM derivacional $r=0,54, p<0,01$ e CM flexional $r=0,51 ; p<0,01$ ) e compreensão de texto (CM derivacional $r=0,42 ; p<0,01$ e CM flexional $r=0,44 ; p<$ $0,01)$. A medida consciência morfológica (derivacional e flexional) também correlacionou significativamente com as outras medidas tomadas. A consciência fonológica e a idade também se correlacionaram com todas as medidas. A inteligência verbal (vocabulário/WISCIII) não correlacionou significativamente com a medida de precisão de leitura de palavras $(r=0,19 ; p<0,33)$ e com a compreensão de texto $(r=0,16 ; p<0,09)$. A inteligência não-verbal (cubo/WISC III) correlacionou significativamente de maneira fraca com a precisão de leitura de palavras (cubo $r=0,27 ; p<0,01$ ) e moderada com a compreensão de texto (cubo $r=0,40 ; p<0,05$ ).

Análises de regressão hierárquica foram conduzidas para investigar se consciência morfológica é uma habilidade cognitiva preditora das medidas de leitura. Quatro análises de regressão hierárquica foram realizadas, duas para cada medida de leitura: precisão de palavras e compreensão de texto. As variáveis de controle foram à idade, inteligência (verbal e não verbal) e a consciência fonológica, por que elas se correlacionaram com as medidas de consciência morfológica. O objetivo do controle foi de neutralizar a influência de uma variável sobre a outra. Os resultados são apresentados na tabela 3.
Tabela 3. Resumo dos Resultados das Análises de Regressão Hierárquica com os Preditores de Leitura.

\begin{tabular}{|c|c|c|c|c|c|c|}
\hline \multirow[t]{2}{*}{ Preditor/Passos } & \multicolumn{3}{|c|}{$\begin{array}{l}\text { Precisão de leitura de } \\
\text { palavras }\end{array}$} & \multicolumn{3}{|c|}{ Compreensão de texto } \\
\hline & $\Delta \mathrm{R}^{2}$ & $\beta$ & Sig. & $\Delta \mathrm{R}^{2}$ & $\beta$ & Sig. \\
\hline $1^{\circ}$ Idade (meses) & 0,18 & 0,42 & 0,001 & 0,13 & 0,36 & 0,001 \\
\hline $2^{\circ}$ Intel. & 0,05 & & 0,035 & 0,12 & & 0,001 \\
\hline Cubo/WISCIII & & 0,12 & 0,22 & & 0,27 & 0,03 \\
\hline Vocabulário/WISCIII & & 0,22 & 0,014 & & 0,30 & 0,02 \\
\hline $3^{\circ} \mathrm{CF} 1$ & 0,16 & 0,47 & 0,001 & 0,019 & 0,16 & 0,10 \\
\hline $4^{\circ}$ a CMD & 0,037 & 0,26 & 0,010 & 0,011 & 0,15 & 0,22 \\
\hline $4^{\circ} \mathrm{b} C M F$ & 0,008 & 0,13 & 0,23 & 0,010 & 0,15 & 0,20 \\
\hline $3^{\circ} \mathrm{CF} 2$ & 0,11 & 0,39 & 0,001 & 0,096 & 0,37 & 0,001 \\
\hline $4^{\circ} \mathrm{C} C M D$ & 0,015 & 0,18 & 0,09 & 0,006 & 0,11 & 0,36 \\
\hline $4^{\circ} \mathrm{d} \mathrm{CMF}$ & 0,03 & 0,08 & 0,46 & 0,007 & 0,13 & 0,30 \\
\hline $3^{\circ} \mathrm{CM}$ & 0,13 & & 0,001 & 0,032 & & 0,09 \\
\hline Derivacional & & 0,35 & 0,001 & & 0,19 & 0,66 \\
\hline Flexional & & 0,42 & 0,001 & & 0,20 & 0,60 \\
\hline $4^{\circ} \mathrm{CF} 1$ & 0,063 & 0,35 & 0,001 & 0,002 & 0,63 & 0,60 \\
\hline $4^{\circ} \mathrm{CF} 2$ & 0,095 & 0,48 & 0,001 & 0,005 & 0,11 & 0,40 \\
\hline
\end{tabular}

Nota. Intel = inteligência (Cubo/WISCIII e vocabulário/WISCIII) CF1 = consciência fonológica/Spoonerismo $1^{\text {a }}$ parte; $\mathrm{CF} 2$ = consciência fonológica/ Spoonerismo $2^{\mathrm{a}}$ parte; $\mathrm{CMD}=$ consciência morfológica derivacional/Analogia derivacional; $\mathrm{CMF}$ = consciência morfológica/analogia flexional.

As duas primeiras análises foram desenhadas com os seguintes passos: $1^{\circ}$ passo - idades (meses), $2^{\circ}$ passo - a inteligência não-verbal (cubo/WISCIII) e verbal (vocabulário/WISCIII), $3^{\circ}$ passo - a $1^{\text {a }}$ parte do Spoonerismo e $4^{\circ}$ passo - uma das medidas de

Tabela 2. Correlações (Pearson) entre as Variáveis de Leitura e as Habilidades Metalinguísticas.

\begin{tabular}{|c|c|c|c|c|c|c|c|c|c|}
\hline Medidas & 1 & 2 & 3 & 4 & 5 & 6 & 7 & 8 & 9 \\
\hline 1. CF 1 & - & & & & & & & & \\
\hline 2. CF 2 & $0,75^{* *}$ & - & & & & & & & \\
\hline 3. CMD & $0,61^{* *}$ & $0,71^{* *}$ & - & & & & & & \\
\hline 4. CMF & $0,67^{* *}$ & $0,69^{* *}$ & $0,70^{* *}$ & - & & & & & \\
\hline 5. L. palavras & $0,58^{* *}$ & $0,64^{* *}$ & $0,54^{* *}$ & $0,51^{* *}$ & - & & & & \\
\hline 6. C. texto & $0,38^{* *}$ & $0,44^{* *}$ & $0,42^{* *}$ & $0,44^{* *}$ & $0,46^{* *}$ & - & & & \\
\hline 7. Vocabulário & 0,15 & $0,22^{*}$ & $0,19^{*}$ & $0,20^{*}$ & 0,19 & 0,16 & - & & \\
\hline 8. Cubo & $0,39 * *$ & $0,44^{* *}$ & $0,45^{* *}$ & $0,43^{* *}$ & $0,27^{* *}$ & $0,40^{* *}$ & 0,42 & - & \\
\hline 9. Idade (meses) & $0,43^{* *}$ & $0,47^{* *}$ & $0,41^{* *}$ & $0,50^{* *}$ & $0,43^{* *}$ & $0,36^{* *}$ & $0,26^{* *}$ & $0,40^{* *}$ & - \\
\hline
\end{tabular}

Nota. CF1 = consciência fonológica/Spoonerismo $1^{\text {a }}$ parte; CF2 = consciência fonológica/Spoonerismo $2^{\text {a }}$ parte; $\mathrm{CMF}=$ consciência morfológica flexional; CMD = consciência morfológica derivacional; L. palavra = leitura de palavras; C. texto = compreensão de texto; ${ }^{* *} p<0,01 ;{ }^{*} p<0,05$. 
consciência morfológica. Esse último passo foi alternado com as medidas de consciência morfológica derivacional e flexional. Nesses modelos, as medidas de consciência morfológica derivacional foram significativas apenas para precisão de leitura (CM derivacional $\Delta R^{2}=0,037$; $\beta=0,26 ; p=0,01$ ) não para compreensão de texto (CM derivacional $\Delta \mathrm{R}^{2}=0,011 ; \beta=0,15 ; p=0,22$ ). As medidas de consciência morfológica flexional não atingiram significância estatística para as duas medidas de leitura, na precisão de leitura de palavras (CM flexional $\Delta R^{2}=$ 0,$008 ; \beta=0,13 ; p=0,23$ ) e na compreensão de texto (CM flexional $\Delta \mathrm{R}^{2}=0,010 ; \beta=0,15 ; p=0,20$ ).

As duas últimas regressões hierárquicas respeitaram os mesmos passos das anteriores, apenas trocando a medida de consciência fonológica, que foi a $2^{\text {a }}$ parte do Spoonerismo. As análises mostraram que as medidas de consciência morfológica não foram significativas para precisão de leitura (CM derivacional $\Delta \mathrm{R}^{2}=0,015 ; \beta=0,18 ; p=0,09$ e CM flexional $\Delta \mathrm{R}^{2}=0,03$; $\beta=0,08 ; p=0,46$ ) e para compreensão de texto (CM derivacional $\Delta \mathrm{R}^{2}=0,006 ; \beta=0,11 ; p=0,36$ e $\mathrm{CM}$ flexional $\Delta R^{2}=0,007 ; \beta=0,13 ; p=0,30$ ), quando a medida incluída de consciência fonológica foi a $2^{a}$ parte da tarefa de Spoonerismo.

Os resultados indicaram que apenas a consciência morfológica derivacional contribuiu para a leitura de palavras, explicando $3,7 \%$, porém o mesmo não aconteceu com a medida de compreensão de texto. Isso significa que, mesmo após a retirada da influência da idade, da inteligência (não-verbal e verbal) e da consciência fonológica, a consciência morfológica derivacional resistiu em contribuir para a variável de leitura de palavras. A consciência morfológica flexional não conseguiu explicar, de maneira independente e significativa $(p>0,05)$, a leitura de palavras e compreensão de texto, após o uso das variáveis de controle.

Para compreender se a consciência fonológica continua a contribuir para a leitura, sem a influência da consciência morfológica, foram realizadas duas análises de regressão hierárquicas, invertendo a ordem de entrada das habilidades metalinguísticas. A precisão de leitura de palavras e compreensão de texto foram as variáveis de critérios. Os resultados são apresentados na tabela 3. Eles demonstram que a consciência fonológica continua explicando a variação nos escores da precisão de leitura de palavras (6,3\% e 9,5\%), depois de controlada a influência da contribuição da idade, inteligência (verbal e não-verbal) e das medidas de consciência morfológica (derivacional e flexional), (CF $1^{\text {a }}$ parte da tarefa de Spoonerismo $\Delta \mathrm{R}^{2}=0,063 ; \beta=0,35 ; p=0,001$ e CF $2^{a}$ parte da tarefa de Spoonerismo $\Delta R^{2}=0,095$; $\beta=0,48 ; p=0,001$ ). Todavia, para a compreensão de texto, a contribuição da consciência fonológica não foi significativa (CF $1^{\text {a }}$ parte da tarefa de Spoonerismo $p=$ 0,60 e CF $2^{\text {a }}$ parte da tarefa de Spoonerismo $p=0,40$ ). A tabela 3 mostra o resultado das regressões.

\section{Discussão}

A finalidade do presente estudo foi de averiguar se, após os controles das influências da idade, inteligência (verbal e não verbal), consciência fonológica, a consciência morfológica apresentaria contribuições independentes para explicar a precisão de leitura de palavras e compreensão de texto no português do Brasil. Os resultados mostraram que a consciência morfológica teve uma contribuição independente apenas para a medida de precisão de leitura e não para a compreensão de texto. Esses achados, que corroboraram alguns resultados de estudos nacionais (Miranda \& Mota, 2013; Mota et al. 2012) e internacionais (Deacon \& Kirby, 2004; Kirby et al., 2012), tentam responder as ponderações de Justi e Roazzi (2012) sobre as lacunas nos estudos sobre consciência morfológica e leitura, referentes à necessidade de mais variáveis de controle.

Mesmo controlando a influência da inteligência e da consciência fonológica, a consciência morfológica derivacional continuou a contribuir para a leitura de palavras no presente estudo. Os resultados, quando a consciência morfológica flexional foi avaliada, não foram significativos. Também não foram significativos quando se avaliou a compreensão de textos. Esses resultados corroboram estudos anteriores de Freitas e Mota (2015) no que tange à morfologia flexional e à compreensão de texto.

Os dados deste estudo revelaram que a consciência morfológica derivacional de crianças do $2^{\circ}$ e $4^{\circ}$ anos explicou $3,7 \%$ da leitura de palavras, após os controles da idade, inteligência (verbal e não verbal) e consciência fonológica (Spoonerismo $1^{a}$ parte). Essa contribuição é pequena, se comparada com o resultado da influência da consciência fonológica $(6,3 \%$ e $9,5 \%)$ na leitura de palavras, mas não pode ser ignorada. Em línguas alfabéticas, a consciência morfológica apresenta uma proporção maior da variância na leitura, pela própria natureza do princípio alfabético que envolve conectar letras aos sons. O fato de a consciência morfológica continuar a contribuir, sem a influência da consciência fonológica, destaca sua importância. 
Poder-se-ia esperar que a consciência morfológica contribuísse para a compreensão de leitura. Há evidências dessa relação no inglês (Tong et al. 2011). Esperava-se que ambas as medidas de habilidades metalinguísticas (consciência morfológica e fonológica) contribuíssem para a compreensão de texto, como nos estudos internacionais de Deacon e Kirby (2004) e Kirby et al. (2012) com crianças falantes do inglês. No presente estudo, nenhuma das medidas metalinguísticas foi significativa. O mesmo aconteceu em Freitas e Mota (2015). O estudo não encontrou uma relação entre consciência morfológica e compreensão de texto. Isso pode nos indicar que, no português, a manipulação explícita dos morfemas pode não estar relacionada diretamente com a compreensão de texto. Nesse sentido, a consciência morfológica poderia ter um papel indireto via leitura de palavra, como discutem Freitas e Mota (2015). Nesse caso, um estudo que utilizasse a análise de equação estrutural poderia responder a essa hipótese.

A consciência morfológica flexional não obteve resultado significativo para nenhuma das duas medidas de leitura. Uma explicação possível é que a derivação contém um componente semântico que está ausente na flexão. As palavras derivadas possuem mudanças de significado, muitas vezes acompanhadas de mudança gramatical, o que pode incidir na precisão da leitura de palavras. Leitores com desenvolvimento atípico de leitura apresentam maior dificuldade para processar a derivação do que a flexão (Tong et al, 2011). Isso pode indicar que as mudanças flexionais sejam mais previsíveis do que as derivacionais. Apesar de o presente estudo não ter como objetivo investigar os efeitos dos tipos de morfemas, os achados também apontam para as diferenças da consciência morfológica derivacional e da flexional para aquisição da leitura (Mota et al. 2013, Mota e Freitas, 2014). Nesse caso, a nossa hipótese é de que consciência morfológica derivacional, pelo seu papel semântico, talvez seja uma habilidade mais importante para o desenvolvimento da leitura.

É preciso comentar o fato de que, quando se retirou a influência da consciência fonológica pela tarefa de Spoonerismo 2, a contribuição da consciência morfológica deixou de ser significativa. Cabe ressaltar que, como essa tarefa aumenta muito a demanda cognitiva das crianças na hora de realizá-la, pode ter sido por essa razão que esses resultados não foram significativos. Outros estudos devem ampliar as medidas de consciência fonológica para verificar a corroboração dos resultados.
A última observação que faremos, não menos importante, é que, a despeito dos estudos de correlação ou predição oferecerem forte suporte para o papel do conhecimento morfológico no desenvolvimento da alfabetização, eles não podem responder completamente a questão da causalidade entre as variáveis. Nesse sentido, é necessária a realização de estudos de intervenção com crianças brasileiras, para que se possa entender a relação causal entre a consciência morfológica e o desenvolvimento da leitura, bem como estudos que demonstrem a eficácia de intervenções no contexto educacional brasileiro. Com isso, podemos repensar as orientações do ensino da ortografia, em uma perspectiva mais significativa, possibilitando às crianças atingirem níveis de proficiência de leitura apropriados, tendo o direito de exercerem a cidadania em uma sociedade letrada como a nossa.

\section{Considerações finais}

Em que pese o fato da consciência fonológica ser a principal habilidade metalinguística quando investigamos a leitura de palavras, é importante ressaltarmos o papel que a consciência morfológica exerce para o desenvolvimento dessa habilidade. Mesmo quando efetuados controles como a idade, inteligência (verbal e não-verbal) e consciência fonológica, a consciência morfológica ainda contribui de forma independente para o reconhecimento de palavras. Os resultados contraditórios encontrados na literatura apontam para a necessidade de um número maior de estudos sobre o tema. Eles também apontam para a complexidade desse constructo, especialmente, quando consideramos as medidas utilizadas para avaliar constructos como a: leitura de palavras, a compreensão de texto e as próprias habilidades metalinguísticas.

Os resultados deste estudo e de outros publicados recentemente destacam a importância dessa área de investigação. Adicionalmente, salientam a necessidade de mais investigações no âmbito das implicações pedagógicas dos resultados encontrados.

\section{Referências}

Bechara, E. (2009). Moderna gramática Portuguesa. Rio de Janeiro: Novas Fronteiras.

Capellini, S. A., Oliveira, A. M., \& Cuetos, F. (2010). PROLEC: Provas de avaliação dos processos de leitura. São Paulo: Casa do Psicólogo.

Capovilla, A. G. S., \& Capovilla, F. C. (1998). Treino de consciência fonológica de pré a segunda série: efeitos sobre habilidades fonológicas, leitura e escrita. Temas Sobre Desenvolvimento, 7(40), 5-15. 
Cardoso-Martins, C. (1995). Consciência fonológica e alfabetização. Rio de Janeiro: Vozes.

Cardoso-Martins, C., Mesquita, T. C. L., \& Ehri, L. (2011). Letter names and phonological awareness help children to learn letter sound relations. Journal of Experimental Child Psychology, 109(1), 25-38. doi: 10.1016/j.jecp.2010.12.006.

Carlisle, J. (1995). Morphological awareness and early reading achievement. In L. Feldman (Org.), Morphological aspects of language processing (pp. 189-209). Hillsdale: Lawrence Erlbaum Associates.

Deacon, S. H., Benere, J., \& Pasquarella, A. (2013). Reciprocal relationship: children's morphological awareness and their reading accuracy across grades 2 to 3. Developmental Psychology, 49(6), 1113-1126. doi: 10.1037/a0029474

Deacon, S. H., \& Kirby, J. R. (2004). Morphological awareness: just "more phonological"? The roles of morphological and phonological awareness in reading development. Applied Psycholinguistics, 25(2), 223-238. doi: 10.1007/s11145-010-9276-5

Field, A. (2009). Descobrindo estatística usando o SPSS (2ª ed.). Porto Alegre: Armed.

Freitas Jr., P.V., \& Mota, M. M. P.E. (2015). So, morphological awareness contributes to reading in Brazilian Portuguese? Psico-USF, 20(3), 471-479. doi: 10.1590/1413-82712015200309

Justi, C., \& Roazzi, A. (2012). A contribuição de variáveis cognitivas para a leitura e a escrita no Português Brasileiro. Psicologia: Reflexão e Crítica, 25(3), 605-614. doi: 10.1590/S0102-79722012000300021

Kirby, J., Deacon, S. H., Bowers, P., Izenberg, L., Wade-Woolley, L., \& Parrilla, R. (2012). Children morphological awareness and reading ability. Reading and Writing: An Interdisciplinary Journal, 25(2), 389410. doi: 10.1007/s11145-010-9276-5

Kruk, R., \& Bergman, K. (2013). The reciprocal relationships between morphological awareness and reading. Journal of Experimental Child Psychology, 114(1), 10-34. doi: 10.1016/j.jecp.2012.09.014

Kuo, L., \& Anderson, R. C. (2006). Morphological awareness and learning to read: a cross-language perspective. Educational Psychologist, 41(3), 161-180. doi: 10.1207/s15326985ep4103_3

Laroca, M. (2005). Manual de morfologia do Português. Campinas: Pontes.

Mahony, D., Singson, M., \& Mann, V. (2000). Reading ability and sensitivity to morphological relations. Reading and Writing: an Interdisciplinary Journal, 12(3-4), 191-218. doi: 10.1023/A:1008136012492

Maluf, M.R., \& Barrera, S. D. (1997). Consciência fonológica e linguagem escrita em pré-escolares. Psicologia: Reflexão e Crítica, 10(1), 125145. doi: 10.1590/S0102-79721997000100009

Miranda, L., \& Mota, M. (2013). Há uma relação específica entre consciência morfológica e reconhecimento de palavras? Psico-USF, 18(2), 241-248. doi: 0.1590/S1413-82712013000200008

Mota, M., Anibal, L., \& Lima, S. (2008). A morfologia derivacional contribui para a leitura e escrita no português? Psicologia: Reflexão e Crítica, 21(2), 311-318. doi: 10.1590/S0102-79722008000200017
Mota, M., \& Freitas Junior, P. V. (2014). Há contribuições diferentes da morfologia derivacional e flexional para a escrita? Psicologia em Pesquisa, 8(2), 144-149. doi: 10.5327/Z1982-1247201400020003

Mota, M., Guimarães, S., Conti, C., Linhares, T., Rezende, L., Amorin, S., ... Gumier, A. (2013). Diferenças entre o desenvolvimento da morfologia derivacional e flexional no português brasileiro no ensino fundamental. Psicologia: Reflexão e Crítica, 26(4), 730-734. doi: 10.1590/S0102-79722013000400013

Mota, M., Santos, A. A. A., Dias, J., Paiva, N., Mansur-Lisboa, S., \& Andrade Silva, D. (2008). Relação entre consciência morfológica e a escrita em crianças do ensino fundamental. Psicologia em Pesquisa, 2(2), 51-60. Recuperado de http://pepsic.bvsalud.org/ scielo.php?script=sci_arttext\&pid=S1982-12472008000200006\&ln $\mathrm{g}=\mathrm{pt} \&$ tIng $=\mathrm{pt}$.

Mota, M., Toledo, M., Bastos, R., Dias, J., Paiva, N., Mansur-Lisboa, S. F., \& Silva, D. A. (2012). Leitura contextual e processamento metalinguístico no Português do Brasil: um estudo longitudinal. Psicologia: Reflexão e Crítica, 25(1), 114-120. doi: 10.1590/S010279722012000100014.

Nagy, W., Berninger, V., \& Abbot, R. (2006). Contributions of morphology beyond phonology to literacy outcome of upper elementary and middle-school students. Journal of Educational Psychology, 98(1), 34-147.

Nunes, T., Bindman, M., \& Bryant, P. (1997). Morphological strategies: developmental stages and processes. Developmental Psychology, 33(4), 637-649. doi: 10.1037//0012-1649.33.4.637

Nunes, T., \& Bryant, P. (2006). Improving literacy by teaching morphemes. Londres: Routlege

Nunes, T., Bryant, P., \& Barros, R. (2012). The development of word recognition and its significance for comprehension and fluency. Journal of Educational Psychology, 104(4), 959-973. doi: 10.1037/a0027412

Rego, L., \& Buarque, L. (1997). Consciência sintática, consciência fonológica e aquisição de regras ortográficas. Psicologia: Reflexão e Crítica, 10(2), 199-217. doi: 10.1590/S0102-79721997000200003

Roazzi, A., Roazzi, M. M., Justi, C., \& Justi, F. (2013). A relação entre a habilidade de leitura e a consciência fonológica: estudo longitudinal em crianças pré-escolares. Estudo e Pesquisas em Psicologia, 13(2), 420-445. Recuperado de http://www.revispsi.uerj.br/v13n2/artigos/ $\mathrm{html} / \mathrm{v} 13 \mathrm{n} 2 \mathrm{a} 03 . \mathrm{html}$

Seymour, P., Aro, M., \& Erskine, J. M. (2003). Foundation literacy acquisition in European orthographies. British Journal of Psychology, 94(2), 143-174. doi: 10.1348/000712603321661859

Stein, L. (1994). Teste de desempenho escolar. São Paulo: Casa do Psicólogo.

Tong, X., Deacon, S., Kirby, J., Cain, K., \& Parrila, R. (2011). Morphological awareness: a key to understanding poor reading comprehension in English. Journal of Educational Psychology, 103(3), 523-534. doi: 10.1037/a0023495

Wechsler, D. (1991). WISC-III: Escala de inteligência Weschsler para crianças. São Paulo: Casa do Psicólogo. 
Silvia Brilhante Guimarães, Doutora em Psicologia pela Universidade do Estado do Rio de Janeiro (UERJ), Pós-doutoranda em Psicologia pela Universidade Salgado de Oliveira (UNIVERSO), é Bolsista de pósdoutorado/CAPES na Universidade Salgado de Oliveira (UNIVERSO). Endereço para correspondência: Rua: Senador Vergueiro, 148, apt ${ }^{\circ} 904$, Flamengo. Rio de Janeiro (RJ). E-mail: silvia_brilhante@yahoo.com.br

Márcia Maria Peruzzi Elia da Mota, Doutora em Psicologia pela Oxford University, Pós-Doutorado pela Dallhousie Universitie, é Professora do Programa de Pós-Graduação em Psicologia da Universidade Salgado de Oliveira (UNIVERSO) e Diretora do Instituto de Psicologia da Universidade do Estado do Rio de Janeiro (UERJ). E-mail: mmotapsi@gmail.com 